Network Working Group

Request for Comments: 3674

Category: Standards Track
K. Zeilenga

OpenLDAP Foundation

December 2003

Feature Discovery in Lightweight Directory Access Protocol (LDAP)

Status of this Memo

This document specifies an Internet standards track protocol for the Internet community, and requests discussion and suggestions for improvements. Please refer to the current edition of the "Internet Official Protocol Standards" (STD 1) for the standardization state and status of this protocol. Distribution of this memo is unlimited.

Copyright Notice

Copyright (C) The Internet Society (2003). All Rights Reserved.

Abstract

The Lightweight Directory Access Protocol (LDAP) is an extensible protocol with numerous elective features. This document introduces a general mechanism for discovery of elective features and extensions which cannot be discovered using existing mechanisms.

1. Background and Intended Use

The Lightweight Directory Access Protocol (LDAP) [RFC3377] is an extensible protocol with numerous elective features. LDAP provides mechanisms for a client to discover supported protocol versions, controls, extended operations, Simple Authentication and Security Layer (SASL) mechanisms, and subschema information. However, these mechanisms are not designed to support general feature discovery.

This document describes a simple, general-purpose mechanism which clients may use to discover the set of elective features supported by a server. For example, this mechanism could be used by a client to discover whether or not the server supports requests for all operational attributes, e.g., "+" [RFC3673]. As another example, this mechanism could be used to discover absolute true, e.g., "(\&)" and false, e.g.,"(|)", search filters [T-F] support.

This document extends the LDAP Protocol Mechanism registry [RFC3383] to support registration of values of the supportedFeatures attribute. This registry is managed by the Internet Assigned Numbers Authority (IANA) . 
Schema definitions are provided using LDAP description formats [RFC2252]. Definitions provided here are formatted (line wrapped) for readability.

The key words "MUST", "MUST NOT", "REQUIRED", "SHALL", "SHALL NOT", "SHOULD", "SHOULD NOT", "RECOMMENDED", "MAY", and "OPTIONAL" in this document are to be interpreted as described in BCP 14 [RFC2119].

\section{Discovery of supported features}

Each elective feature whose support may be discovered SHALL be identified by an Object Identifier (OID). A server advertises its support for a given feature by providing the OID associated with the feature as a value of the 'supportedFeatures' attribute held in the root DSE. A client may examine the values of this attribute to determine if a particular feature is supported by the server. A client MUST ignore values it doesn't recognize as they refer to elective features it doesn't implement.

Features associated with standard Track protocol mechanisms MUST be registered. Features associated with other protocol mechanisms SHOULD be registered. Procedures for registering protocol mechanisms are described in BCP 64 [RFC3383]. The word "Feature" should be placed in the usage field of the submitted LDAP Protocol Mechanism template.

The 'supportedFeatures' attribute type is described as follows:

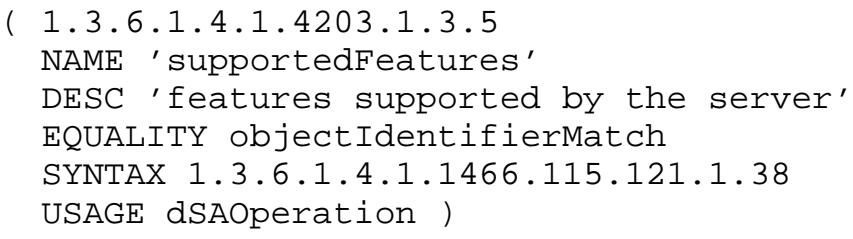

Servers MUST be capable of recognizing this attribute type by the name 'supportedFeatures'. Servers MAY recognize the attribute type by other names.

3. Security Considerations

As rogue clients can discover features of a server by other means (such as by trial and error), this feature discovery mechanism is not believed to introduce any new security risk to LDAP. 


\section{IANA Considerations}

\subsection{Registration of Features as Protocol Mechanisms}

Future specifications detailing LDAP features are to register each feature as a LDAP Protocol Mechanism per guidance given in BCP 64 [RFC3383]. A usage of "Feature" in a Protocol Mechanism registration template indicates that the value to be registered is associated with an LDAP feature.

4.2. Registration of the supportedFeatures descriptor

The IANA has registered the LDAP 'supportedFeatures' descriptor. The following registration template is suggested:

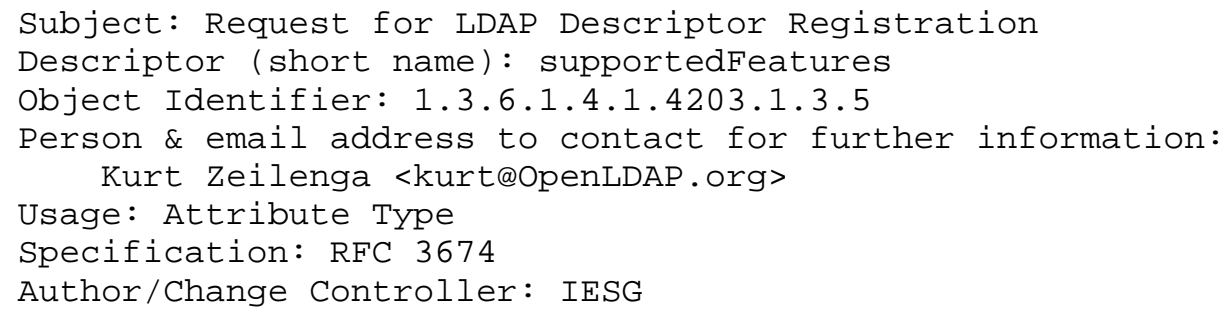

This OID was assigned [ASSIGN] by OpenLDAP Foundation under its IANA assigned private enterprise allocation [PRIVATE] for use in this specification.

5. Acknowledgment

This document is based upon input from the IETF LDAPEXT working group.

6. Intellectual Property statement

The IETF takes no position regarding the validity or scope of any intellectual property or other rights that might be claimed to pertain to the implementation or use of the technology described in this document or the extent to which any license under such rights might or might not be available; neither does it represent that it has made any effort to identify any such rights. Information on the IETF's procedures with respect to rights in standards-track and standards-related documentation can be found in BCP-11. Copies of claims of rights made available for publication and any assurances of licenses to be made available, or the result of an attempt made to obtain a general license or permission for the use of such proprietary rights by implementors or users of this specification can be obtained from the IETF secretariat. 
The IETF invites any interested party to bring to its attention any copyrights, patents or patent applications, or other proprietary rights which may cover technology that may be required to practice this standard. Please address the information to the IETF Executive Director.

7. References

\subsection{Normative References}

[RFC2119] Bradner, S., "Key words for use in RFCs to Indicate Requirement Levels", BCP 14, RFC 2119, March 1997.

[RFC2252] Wahl, M., Coulbeck, A., Howes, T. and S. Kille, "Lightweight Directory Access Protocol (v3): Attribute Syntax Definitions", RFC 2252, December 1997.

[RFC3377] Hodges, J. and R. Morgan, "Lightweight Directory Access Protocol (v3): Technical specification", RFC 3377, September 2002 .

[RFC3383] Zeilenga, K., "Internet Assigned Numbers Authority (IANA) Considerations for Lightweight Directory Access Protocol (LDAP)", BCP 64, RFC 3383, September 2002 .

\subsection{Informative References}

[RFC3673] Zeilenga, K., "Lightweight Directory Access Protocol version 3 (LDAPV3): All Operational Attributes", RFC 3673, December 2003.

[T-F] Zeilenga, K., "LDAP True/False Filters", Work in Progress.

[ASSIGN] OpenLDAP Foundation, "OpenLDAP OID Delegations", http://www. openldap.org/foundation/oid-delegate.txt.

[PRIVATE] IANA, "Private Enterprise Numbers", http://www.iana.org/assignments/enterprise-numbers.

8. Author's Address

Kurt D. Zeilenga

OpenLDAP Foundation

EMail: Kurt@OpenLDAP.org 
9. Full Copyright statement

Copyright (C) The Internet Society (2003). All Rights Reserved.

This document and translations of it may be copied and furnished to others, and derivative works that comment on or otherwise explain it or assist in its implementation may be prepared, copied, published and distributed, in whole or in part, without restriction of any kind, provided that the above copyright notice and this paragraph are included on all such copies and derivative works. However, this document itself may not be modified in any way, such as by removing the copyright notice or references to the Internet society or other Internet organizations, except as needed for the purpose of developing Internet standards in which case the procedures for copyrights defined in the Internet standards process must be followed, or as required to translate it into languages other than English.

The limited permissions granted above are perpetual and will not be revoked by the Internet society or its successors or assignees.

This document and the information contained herein is provided on an "AS IS" basis and THE INTERNET SOCIETY AND THE INTERNET ENGINEERING TASK FORCE DISCLAIMS ALL WARRANTIES, EXPRESS OR IMPLIED, INCLUDING BUT NOT LIMITED TO ANY WARRANTY THAT THE USE OF THE INFORMATION HEREIN WILL NOT INFRINGE ANY RIGHTS OR ANY IMPLIED WARRANTIES OF MERCHANTABILITY OR FITNESS FOR A PARTICULAR PURPOSE.

Acknowledgement

Funding for the RFC Editor function is currently provided by the Internet Society. 